\title{
AUTHOR INDEX FOR VOLUME 92
}

ABDO, H. and DIMITROV, D.; Nonregular graphs with minimal total irregularity

ABTAHI, F. and GHAFARPANAH, A.; A note on cyclic amenability of the Lau product of Banach algebras defined by a Banach algebra morphism

ALI, K.; see RIZVI, S. T. R.

282

ALMEIDA, J. and COSTA, A.; A note on pseudovarieties of completely regular semigroups

AN, M. and XIONG, L.; Some results on the difference of the Zagreb indices of a graph

BROERSMA, H.; see ZHANG, Y.

BROWN, P. G.; see IZADI, F.

CAICEDO, A. and VIANA, A.; A diffusive logistic equation with memory in Bessel potential spaces

CAO, X. and XU, G.; A note on some character sums over finite fields

CHAND, A. K. B.; see NAVASCUÉS, M. A.

CHEN, J.; see LI, P.

CHEN, J. X. and LI, L.; On a question of Bouras concerning weak compactness of almost Dunford-Pettis sets

CHEN, L.; Quasi Riesz transforms, Hardy spaces and generalised sub-Gaussian heat kernel estimates

CHEN, Y.; see ZHANG, Y.

CHOULLI, M., KAYSER, L. and OUHABAZ, E. M.; Observations on Gaussian upper bounds for Neumann heat kernels

CHRISTENSEN, O., FORSTER, B. and MASSOPUST, P.; Directional timefrequency analysis via continuous frames

CHUNG, J. and SAHOO, P. K.; Heat kernel method for the Levi-Civitá equation in distributions and hyperfunctions

COSTA, A.; see ALMEIDA, J.

CRINGANU, J.; Better bounds in Chen's inequalities for the Euler constant

CRISP, T.; Fredholm modules over graph $C^{*}$-algebras

DARAFSHEH, M. R., GHORBANI, M. and PRAJAPATI, S. K.; On maximal subsets of pairwise noncommuting elements in finite $p$-groups

DIMITROV, D.; see ABDO, H.

DONG, Z. and WANG, Y. Y.; Fixed point characterisation for exact and amenable action

DRAGOMIR, S. S.; see RAÏSSOULI, M.

DRIESSEN, T.; see HOU, D.

FARROKHI D. G., M. and MOGHADDAM, M. R. R.; On the centre of the automorphism group of a group

FINN, C.; One-dimensional stochastic models with open boundaries: integrability, applications and $q$-deformed Knizhnik-Zamolodchikov equations 
FISHMAN, L., MANCE, B., SIMMONS, D. and URBAŃSKI, M.; Shrinking targets for nonautonomous dynamical systems corresponding to Cantor series expansions

FORSTER, B.; see CHRISTENSEN, O. 268

GHAFARPANAH, A.; see ABTAHI, F. 282

GHOBBER, S.; Shapiro's uncertainty principle in the Dunkl setting 98

GHORBANI, M.; see DARAFSHEH, M. R. 380

GILES, J. R.; A weakly uniformly rotund dual of a Banach space 457

GILES, J. R.; On a weakly uniformly rotund dual of a Banach space - retraction 176

GŁAZOWSKA, D. and MATKOWSKI, J.; Uniformly bounded composition $\begin{array}{ll}\text { operators } & 463\end{array}$

HANAFI, R.; Modelling and optimisation of railway crew scheduling 348

HARLEY, K.; Canards in advection-reaction-diffusion systems in one spatial dimension

HASSANZADEH, M. and HATAMIAN, R.; An approach to capable groups and Schur's theorem

HATAMIAN, R.; see HASSANZADEH, M.

HEARD, D.; Morava modules and the $K(n)$-local Picard group

HOU, D. and DRIESSEN, T.; Determining the nucleolus of compromise stable games

HUANG, Y.; Moduli spaces of surfaces

IZADI, F., NAGHDALI, R. F. and BROWN, P. G.; Some quartic Diophantine equations in the Gaussian integers

JO, J. H.; On algebraic invariants for free actions on homotopy spheres $\quad 478$

KALANTAR, M.; On iterated powers of positive definite functions $\quad 440$

KARAVARSAMIS, N.; Methods for estimating occupancy

KASPRZAK, P. and MAĆKOWIAK, P.; Local boundedness of nonautonomous superposition operators in $B V[0,1]$

325

KATIYAR, S. K.; see NAVASCUÉS, M. A. 405

KAYSER, L.; see CHOULLI, M. $\quad 429$

KHALID, M.; see RIZVI, S. T. R.

KUZMAN, B.; On graphs of prime valency admitting a solvable arc-transitive group

LANGFORD, M.; Motion of hypersurfaces by curvature 516

LI, D.-H.; see WU, F.-G.

LI, H.-X.; see ZHANG, L.-L. 238

LI, J.-Z.; see LIU, L. $\quad 123$

LI, L.; see CHEN, J. X. $\quad 111$

LI, P., CHEN, J. and WANG, X.; Quasiconformal solutions of Poisson equations 420

LINDNER, S.; Resolvability properties of similar topologies $\quad 470$

LING, D. and TANG, M.; On minimal asymptotic $g$-adic bases 374

LITA DA SILVA, J.; Limiting behaviour for arrays of upper extended negatively dependent random variables 
LITA DA SILVA, J.; Correction to 'Limiting behaviour for arrays of upper extended negatively dependent random variables'

LIU, L. and LI, J.-Z.; Quotient and pseudo unit in nonunital operator system

LOUIS, J.; A formula for the number of spanning trees in circulant graphs with nonfixed generators and discrete tori

LU, J. and LV, X.; Toeplitz operators between Fock spaces 316

LV, X.; see LU, J.

MAĆKOWIAK, P.; see KASPRZAK, P. 325

MANCE, B.; see FISHMAN, L.

MARCHENKO, V.; Stability of unconditional Schauder decompositions in $\ell_{p}$ spaces

MASSOPUST, P.; see CHRISTENSEN, O.

MATKOWSKI, J.; see GŁAZOWSKA, D.

MILLER, M.; see RIZVI, S. T. R.

MOGHADDAM, A.; An integrable and exactly solvable non-Hermitian BCS Hamiltonian and generalised exclusion statistics

MOGHADDAM, M. R. R.; see FARROKHI D. G., M.

NAGHDALI, R. F; see IZADI, F.

NAVASCUÉS, M. A., VISWANATHAN, P., CHAND, A. K. B., SEBASTIÁN, M. V. and KATIYAR, S. K.; Fractal bases for Banach spaces of smooth functions

OUHABAZ, E. M.; see CHOULLI, M.

PEACHEY, T. C.; A sharp version of Bonsall's inequality

PINELIS, I.; Exact upper and lower bounds on the difference between the arithmetic and geometric means

PRAJAPATI, S. K.; see DARAFSHEH, M. R.

PRZEŹDZIECKI, A. J.; Every countable group is the fundamental group of some compact subspace of $\mathbb{R}^{4}$

QU, Z.; On a partition problem of finite abelian groups

RAÏSSOULI, M. and DRAGOMIR, S. S.; Refining recursively the HermiteHadamard inequality on a simplex

RIZVI, S. T. R., KHALID, M., ALI, K., MILLER, M. and RYAN, J.; On cyclesupermagicness of subdivided graphs

RYAN, J.; see RIZVI, S. T. R.

SAFUAN, H. M.; Mathematical analysis of population growth subject to environmental change

SAHOO, P. K.; see CHUNG, J.

SCHEUER, J.; Quantitative oscillation estimates for almost-umbilical closed hypersurfaces in Euclidean space

SEARSTON, I.; Nonlinear analysis in geodesic metric spaces $\quad 514$

SEBASTIÁN, M. V.; see NAVASCUÉS, M. A. 405

SIMMONS, D.; see FISHMAN, L. 
SOROUSHMEHR, M.; Homomorphisms of $\ell^{1}$-Munn algebras and applications to semigroup algebras

STUART, R. M.; Metastable sets in open dynamical systems and substochastic Markov chains

TANG, H.; Shifted convolution sum of $d_{3}$ and the Fourier coefficient of HeckeMaass forms

TANG, M.; see LING, D.

TARR, G.; Quantile based estimation of scale and dependence 173

URBAŃSKI, M.; see FISHMAN, L. 205

VIANA, A.; see CAICEDO, A. 251

VISWANATHAN, P.; see NAVASCUÉS, M. A.

WANG, L.; Arithmetic properties of partition quadruples with odd parts distinct 353

WANG, X.; see LI, P. $\quad 420$

WANG, Y. Y.; see DONG, Z. 228

WATERS, E. K.; Modelling crowding effects in infectious disease transmission 522

WEIGT, M. and ZARAKAS, I.; Derivations of Fréchet nuclear GB*-algebras 290

WRIGHT, P.; Dimensional characteristics of the nonwandering sets of open billiards

WU, F.-G. and LI, D.-H.; The restricted isometry property for signal recovery with coherent tight frames

XIONG, L.; see AN, M.

$\mathrm{XU}, \mathrm{G}$.; see CAO, X.

XUAN, Z. and ZHENG, J.; On the escaping set of meromorphic functions with direct tracts

ZARAKAS, I.; see WEIGT, M.

290

ZHANG, D.; On hyperstability of generalised linear functional equations in several variables

ZHANG, L.-L. and LI, H.-X.; Weighted pseudo almost periodic solutions for differential equations with piecewise constant arguments

ZHANG, Y., BROERSMA, H. and CHEN, Y.; A note on Ramsey numbers for fans

ZHENG, J.; see XUAN, Z. 


\section{INFORMATION FOR AUTHORS}

The Bulletin of the Australian Mathematical Society aims at quick publication of original research in all branches of mathematics. To ensure speedy publication, only articles which are sufficiently well presented, able to be published without revision, and which are judged by the Editor (often in consultation with an Associate Editor) to be competitive are refereed. This policy is in the interests of authors, as a quick rejection is better than a slow rejection. The Bulletin receives more than five times the material that can be published, therefore there are many commendable papers not accepted. Editorial decisions on acceptance or otherwise are taken quickly, normally within a month of receipt of the paper. Papers are accepted only after peer review.

Manuscripts are accepted for review with the understanding that the same work is not concurrently submitted elsewhere. For a paper to be acceptable for publication, not only should it contain new and interesting results, but also

(i) the exposition should be clear and attractive, and

(ii) the manuscript should be in publishable form, without revision.

Further information regarding these requirements may be found through our website www.austms.org.au/Bulletin. Authors are asked to avoid, as far as possible, the use of mathematical symbols in the title.

Articles should be prepared in $\mathrm{ET}_{\mathrm{E}} \mathrm{X}$ using $\mathcal{A}_{\mathcal{M}} \mathcal{S}$-LTEX packages and submitted as a PDF file via our journal management system, at www.austms.org.au/Publications/Submissions/BAustMS. This permits authors to track their papers through the editorial process. Recent versions of $\mathrm{T}_{\mathrm{E}} \mathrm{X}$ are able to produce PDF files directly. A LTTEX class file for the Bulletin can be downloaded from the website. Authors who need assistance may email the secretary of the Bulletin at editor@bulletin.austms.org.au.

Authors are advised to keep copies of all files of the submitted article; the Bulletin will not accept responsibility for any loss.

\section{EDITORIAL POLICY}

1. References. Arrange references alphabetically (by surname of the first author) and cite them numerically in the text. Ensure the accuracy of the references: authors' names should appear as in the work quoted. Include in the list of references only those works cited, and avoid citing works which are in preparation or submitted. Where the work cited is not readily accessible (for example, a preprint) a copy of the article should be included with your submission.

\section{Abstracts.}

1. Each paper must include an abstract of not more than 150 words, which should contain a brief but informative summary of the contents of the paper, but no inessential details.

2. The abstract should be self-contained, but may refer to the title.

3. Specific references (by number) to a section, proposition, equation or bibliographical item should be avoided.

3. Subject Classification and Key Words. Authors should include a few key words and phrases and one or more classification numbers, following the American Mathematical Society 2010 Mathematics Subject Classification for all codes. Details of this scheme can be found on the web at www.ams.org/msc.

4. Abstracts of PhD Theses. The Bulletin endeavours to publish abstracts of all accepted Australasian $\mathrm{PhD}$ theses in mathematics. One restriction, however, is that the abstract must be received by the Editor within six months of the degree being approved.

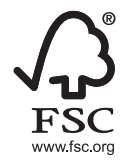

This journal issue has been printed on FSC-certified paper and cover board. FSC is an independent, non-governmental, not-for-profit organisation established to promote the responsible management of the world's forests. Please see www.fsc.org for information. 


\section{Table of Contents}

Arithmetic properties of partition quadruples with odd parts distinct

Wang, $L$.

A formula for the number of spanning trees in circulant graphs with nonfixed generators and discrete tori

Louis, 7.

On minimal asymptotic $g$-adic bases

Ling, D. \& Tang, $M$.

On maximal subsets of pairwise noncommuting elements in finite $\boldsymbol{p}$-groups

Darafsheh, M. R., Ghorbani, M. E Prajapati, S. K.

On the centre of the automorphism group of a group

Farrokhi D. G., M. \& Moghaddam, M. R. R.

A sharp version of Bonsall's inequality

Peachey, T. C.

Fractal bases for Banach spaces of smooth functions

Navascués, M. A., Viswanathan, P., Chand, A. K. B., Sebastián, M. V. \& Kativar, S. K.

Quasiconformal solutions of Poisson equations

Li, P., Chen, 7. \& Wang, $X$.

Observations on Gaussian upper bounds for Neumann heat kernels

Choull, M., Kayser, L. \& Ouhabaz, E. M.

On iterated powers of positive definite functions

Kalantar, $M$.

Stability of unconditional Schauder decompositions in $\ell_{p}$ spaces

Marchenko, V.

A weakly uniformly rotund dual of a Banach space

Giles, 7. R.

Uniformly bounded composition operators

Glazowska, D. \& Matkowski, J.

Resolvability properties of similar topologies

Lindner, $S$.

On algebraic invariants for free actions on homotopy spheres

fo, J. H.

Determining the nucleolus of compromise stable games

Hou, D. E Driessen, T.

The restricted isometry property for signal recovery with coherent tight frames

Wu, F-G. \& Li, D. $-H$.

Abstracts of PhD Theses

Quasi Riesz transforms, Hardy spaces and generalised sub-Gaussian heat kernel estimates

Chen, $L$.

Dimensional characteristics of the nonwandering sets of open billiards

Wright, $P$.

Nonlinear analysis in geodesic metric spaces

Searston, $I$.

Motion of hypersurfaces by curvature

Langford, $M$.

Methods for estimating occupancy

Karavarsamis, $\mathcal{N}$.

One-dimensional stochastic models with open boundaries: integrability, applications and $q$-deformed

Knizhnik-Zamolodchikov equations

Finn, $C$.

Modelling crowding effects in infectious disease transmission

Waters, E. K.

\section{Corrigendum}

Gorrection to 'Limiting behaviour for arrays of upper extended negatively dependent random variables'

Lita da Silva, 7 . 